\title{
Rancang Bangun Sistem Informasi Pengelolaan Berita pada PT TV Kampus Udinus Semarang
}

\author{
Rizal Firdaus $^{1}$, Agus Winarno ${ }^{2}$ \\ ${ }^{1,2}$ Program Studi Sistem Informasi, Universitas Dian Nuswantoro Semarang \\ Jl Imam Bonjol 207 Semarang \\ e-mail: ${ }^{1} 112201505327 @$ mhs.dinus.ac.id, ${ }^{2}$ agus.winarno@dsn.dinu.ac.id
}

Diterima: 7 Nopember 2020; Direvisi: 14 Mei 2020; Disetujui: 20 Mei 2020

\begin{abstract}
Abstrak
Media informasi masa kini sangatlah penting, media informasi dapat menjadi suatu wadah bagi manusia untuk mendapatkan informasi, bertukar pikiran dan bertinteraksi satu sama lainnya. Salah satu media informasi adalah berita, berita merupakan laporan cepat suatu peristiwa atau kejadian yang faktual. PT Televisi Kampus Udinus (TVKU) Semarang merupakan salah satu badan usaha yang bergerak dalam bidang penyiaran dan jasa. PT TVKU dalam melakukan mengelola berita sudah menggunakan alat bantu komputer, yaitu dalam melakukan pengolahan berita, pengolahan jurnalis, pemrosesan berita dan pembuatan laporan yang masih dilakukan dengan cara manual, akan tetapi PT TVKU belum memiliki system pengelolaan berita yang dapat mengintegrasikan setiap proses bisnis yang terjadi. Dari permasalahan tersebut maka perlu terciptanya suatu system informasi yang dapat melakukan pengelolaan berita secara baik, untuk membangun system informasi tersebut menggunakan metode Rapid Application Development $(R A D)$ dengan digabungkan dengan beberapa tools untuk merancang system yaitu dengan menggunakanUnified Modelling Language (UML), untuk bahasa pemrograman menggunakan Hypertext Preprocessor (PHP), dan untuk penyimpanan data menggunakan MySQL sebagai Database Management System (DBMS). Hasil penelitian ini adalah terciptanya system informasi pengelolaan berita yang dapat mengintegrasikan data yang diharapkan mampu membantu kinerja dari PT TVKU Semarang dalam mengelola berita.
\end{abstract}

Kata kunci: rapid application development $(R A D)$, pengelolaan berita

\begin{abstract}
Today's information media are increasingly important, information media can be a place for people to get information, exchange ideas and exchange with one another. One of the information media is news, news is a quick report or factual events. PT Televisi Kampus Udinus (TVKU) Semarang is one of the institutions engaged in broadcasting and services. PT TVKU in managing news has used computer aids, namely in processing news, processing journalists, managing news and making reports that are still done manually, but PT TVKU does not yet have a news transportation system that can help every business process that occurs. From this problem it is necessary to create an information system that can manage news well, to build information systems that use the Rapid Application Development (RAD) method by combining with several tools to manage the system by using Unified Modeling Language (UML), for languages programming using Hypertext Preprocessor (PHP), and for storing data using MySQL as a Database Management System (DBMS). The results of this study are the creation of a news management information system that can integrate data that is expected to help the performance of PT TVKU Semarang in managing news
\end{abstract}

Keywords: rapid application development, news management 


\section{PENDAHULUAN}

Media informasi masa kini sangatlah penting untuk dikembangkan, hal ini dikarenakan melalui media informasi manusia dapat mengetahui informasi dan dapat bertukar pikiran, serta berinteraksi satu sama lain. Salah satu contoh media informasi adalah berita. Berita merupakan laporan cepat dari suatu peristiwa atau kejadian yang faktual, penting dan menarik bagi pembaca menyangkut kepribadian pembaca[1]. Dengan perkembangan teknologi, berita dapat disediakan secara online untuk memudahkan pembaca dalam membaca berita dimanapun dan kapanpun. Untuk mendapatkan berita yang dapat terorganisir, diperlukan suatu pengelolaan terhadap berita. Pengelolaan berita tersebut dilakukan untuk memudahkan pekerja yang berada dilapangan (jurnalis) agar dapat mengirim berita kepada pekerja yang berada dikantor (redaksi) untuk diterbitkan.

PT Televisi Kampus Udinus (TVKU) Semarang merupakan salah satu badan usaha yang bergerak pada bidang penyiaran dan jasa. PT TVKU dalam melakukan manajemen berita sudah menggunakan alat bantu komputer untuk mengelola berita, yaitu pengolahan berita, pengolahan jurnalis, pemrosesan berita dan pembuatan laporan seperti yang ditampilkan pada gambar 1 . Sistem manajemen berita pada PT TVKU masih dinilai sederhana oleh pegawainya dalam mengirim berita dan menggunakan sistem komputerisasi biasa yaitu dengan mengandalkan Microsoft Word, Microsoft Excel, dan e-mail, namun belum terdapatnya sistem informasi yang dapat menunjang pengelolaan berita, khususnya pendataan berita, pendataan jurnalis, dan pembuatan laporan. Hal tersebut membutuhkan waktu yang sangat lama dan beresiko cukup besar jika terdapat kesalahan, kesalahan tersebut merupakan tidak validnya data atau informasi yang didapatkan. Selain terdapat permasalahan pada pengelolaan berita terdapat masalah lain yaitu berita tidak dapat disortir sesuai dengan jenis-jenis berita, dan dalam melakukan pengiriman berita jurnalis harus mengiriman via e-mail terlebih dahulu hal tersebut merupakan salah satu dimana data atau informasi tidak dapat terintegrasi, data tidak terupdate langsung, dan tidak dapat terproses dengan baik. Dengan permasalahan yang sudah dipaparkan maka pada PT TVKU Semarang mengusulkan suatu sistem informasi yang dapat mengelola berita agar dapat terintegrasi dengan baik dengan menghasilkan laporan yang cepat, tepat dan akurat, dimana pada penelitian kali ini akan membuat suatu sistem informasi untuk mengatasi permasalahan tersebut..

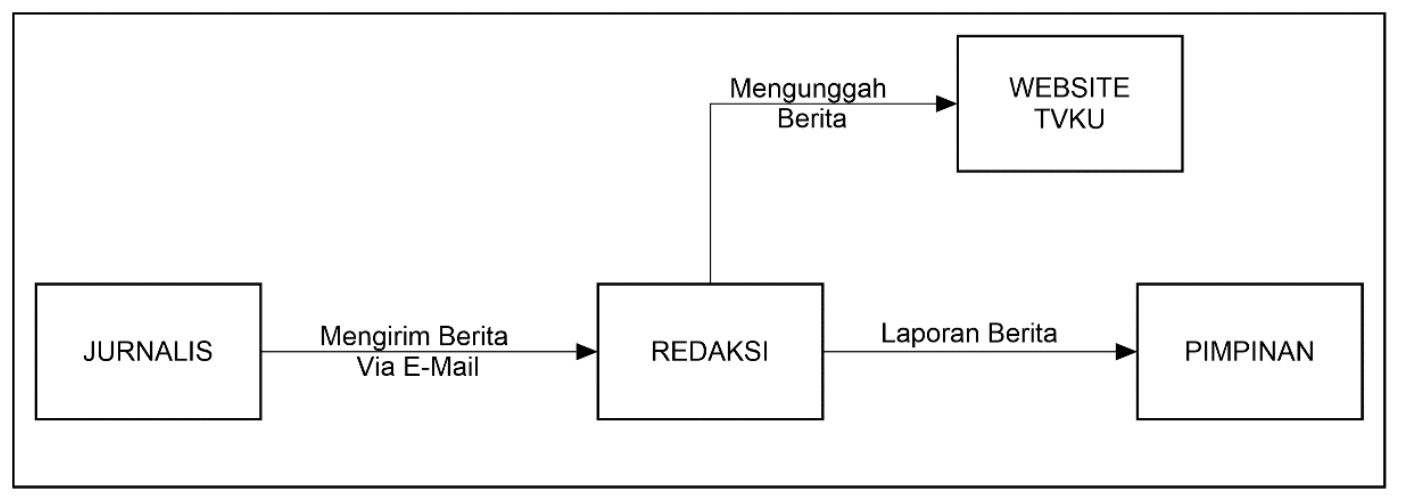

Gambar 1. Proses bisnis pengeloalaan berita pt tvku semarang

Penelitian ini menggunakan metode Rapid Application Development (RAD) untuk mengembangakan sistem infomasi tersebut. RAD adalah salah satu model pengembangan perangkat lunak yang tergolong dalam pengembangan teknik bertingkat [2]. Hasil peneliticn ini diharapkan dapat digunakan untuk memperbaiki proses bisnis yang terjadi pada PT BBI dalam melakukan pengelolaan aset. Penelitian lain yang digunakan sebagai acuan oleh peneliti antara lain Penggunaan Rapid Application Development Perancangan Sistem Informasi Manajemen Berita Berbasis WEB (Studi Kasus Kantor Redaksi Koran Wawasan) [1], Sistem Berita Online 
Berbasis WEB Pada Perguruan Tinggi Raharja[3], Penggunaan Rapid Application Development dalam Rancang Bangun Program Simpan Pinjam Pada Koperasi [4].

\section{METODE PENELITIAN}

Metode yang digunakan dalam penelitian kali ini menggunakan metode Rapid Application development (RAD), metode ini dipilih untuk memperhatikan beberapa faktor seperti diantaranya pemahaman kebutuhan yang mudah dipahami, keterlibatan resiko dan biaya yang rendah. Dengan begitu metode ini sangat sesuai digunakan pada sistem yang kompleks, serta durasi yang pendek untuk pengembangannya, berikut pada gambar 2 merupakan tahapan metode RAD :

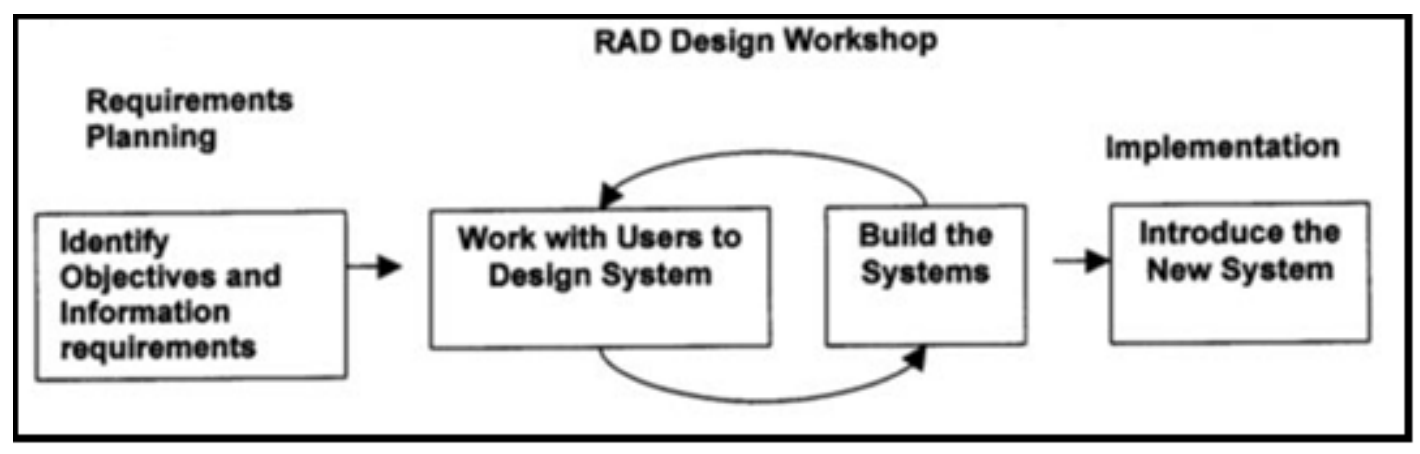

Gambar 2. Metode rapid application development

\subsection{Requipment Planning}

Pada fase requipment planning pengguna sistem dan penganalisis bertemu untuk menentukan tujuan dari dibuatnya penggunaan sistem yaitu memudahkan dalam melakukan pengelolaan data mengenai pengelolaan berita yang dilakukan oleh bagian program dan produksi. Syarat-syarat informasi yang ditimbulkan dari tujuan tersebut untuk dapat menyelesaikan masalah-masalah yang terjadi pada pengelolaan berita bagian program dan produksi.. Perancangan sementara dilakukan dengan berfokus pada proses input dan output dalam pendataan berita. Perancangan dapat dibuat berupa aktivitas proses bisnis yang terjadi serta proses sistem yang dibuat.

\subsection{Workshop Desain RAD}

Pada fase ini dilakukkann workshop desain RAD yang dilakukan untuk menggambarkan usulan dari perancangan sistem secara visual desain dan pola kerja dari proses yang terjadi pada bagian program dan produksi. Fase ini akan menjelaskan kegunaan dari data yang digunakan, proses yang akan diterapkan dalam sistem, dan desain aplikasi yang akan digunakan oleh user. Saat melakukan pemodelan data akan dilakukan apa saja data-data yang digunakan atau dibutuhkan dari pemodelan bisnisnya dengan menentukan atribut yang digunakan dan relasi dengan data-data yang lain. Setelah melakukan pemodelan data selanjutnya akan dilakukan pemodelan proses, pemodelan proses akan melakukan tahapan dalam menerapkan fungsi bisnis yang sudah didefinisikan, terutama yang berkaitan degan pemodelan pada data yang akan digunakan. Setelah melakukan pemodelan proses selanjutnya dilakukan pemodelan aplikasi, pemodelan aplikasi akan menerapkan sesuai dengan yang sudah dilakukan pada pemodelan data dan pemodelan proses yang siap untuk diimplementasikan.

\subsection{Implementation}


Pada fase implementation akan dilakukan implementasi aplikasi yang dimana sudah disesuaikan pada tahapan workshop desain, dimana pengujian dilakukan terhadap komponenkomponen yang sudah dibuat. Apabila pengujian ini dapat dilakukan dengan baik maka selanjutnya dapat melakukan tahapan selanjutnya, fase ini dapat digunakan untuk dijadikan review oleh pemakai (user), pemakai akan melihat apakah aplikasi yang sudah dibuat terdapat kekurangan dalam mendukung proses bisnis yang berjalan.

\section{HASIL DAN PEMBAHASAN}

Pada penelitan kali ini mendapatkan hasil sebagai berikut

\subsection{Initial State}

\section{A. Requierement Planning}

Pada tahapan ini menghasilkan analisis masalah, kebutuhan fungsional dan nonfungsional.

a. Identitifikasi Masalah

Identifikasi masalah dilakukan untuk dapat mengidentifikasi dan mengevaluasi diantaranya adalah :

1. Proses pendataan berita

Proses pendataaan berita dilakukan untuk mengisikan berita atau kejadian secara langsung dari tempat kejadian melalui website oleh jurnalis atau reporter.

2. Proses pemantauan jurnalis

Pemantauan jurnalis dilakukan untuk memastikan data dan informasi yang benar pada setiap berita yang sudah dituliskan oleh jurnalis.

3. Proses pemrosesan berita

Pemrosesan berita dilakukan setelah berita sudah diverifikasi oleh redaksi agar dapat dilakukan pada saat pra penayangan.

4. Penyusunan atau pembuatan laporan

Membuat laporan untuk pimpinan dilakukan berulang sehingga membutuhkan waktu yang cukup lama.

b. Sistem Yang Diusulkan

System yang diusulkan membagun system informasi berbasis website [6], untuk membantu meningkatkan kinerja pada departemen produksi dan program dalam melakukan pengelolaan berita hingga pembuatan laporan yang dilakukan secara cepat.

c. Analisa Kebutuhan Fungsional

Pengambaran kebutuhan system yang akan diterapkan baik analisa kebutuhan data dan pemodelan terhadap system dengan menggunakan unified modelling language (UML) terhadap system informasi pengelolaan berita pada PT TVKU Semarang [5]:

1. Mengelola berita yang sudah dituliskan oleh jurnalis pada di website.

2. Mengelola data-data jurnalis.

3. Melakukan pemrosesan berita yang baik.

4. Memberikan laporan secara akurat, tepat dan cepat untuk diberikan terhadap pimpinan.

d. Analisa Kebutuhan Non Fungsional

Menggambarkan kebutuhan system, diantaranya adalah kebutuhan perangkat lunak, perangkat keras, serta pengguna sistem (user) dalam sistem informasi pendataan berita PT TVKU Semarang:

1. Keakuratan (Accuracy) data.

2. Kemudahan (Easiness) dalam pembuatan laporan

3. Cepat (Quick) dalam melakukan proses mengelola berita. 
4. Tampilan layar (User Interface) didesain secara user friendly.

5. Pemeliharaan (Maintenance).

\section{B. Workshop Desain RAD}

Menggambarkan usulan dari perancangan sistem pada bagian program dan produksi. Menjelaskan proses dan desain aplikasi yang akan digunakan oleh user.Pemodelan menggunakan Unified Modeling Language (UML) yang meliputi usecase diagram, activity diagram, class diagram, sequence diagram yang nantinya akan digunakan dalammengkomunikasikan desain sistem kepada beberapa level, baik itu pengembangmaupun user.

\section{a. Use Case Diagram}

Pada use case diagram terdapat beberapa aktor, yaitu superadmin, redaksi, jurnalis, eksekutif, dan dubber.

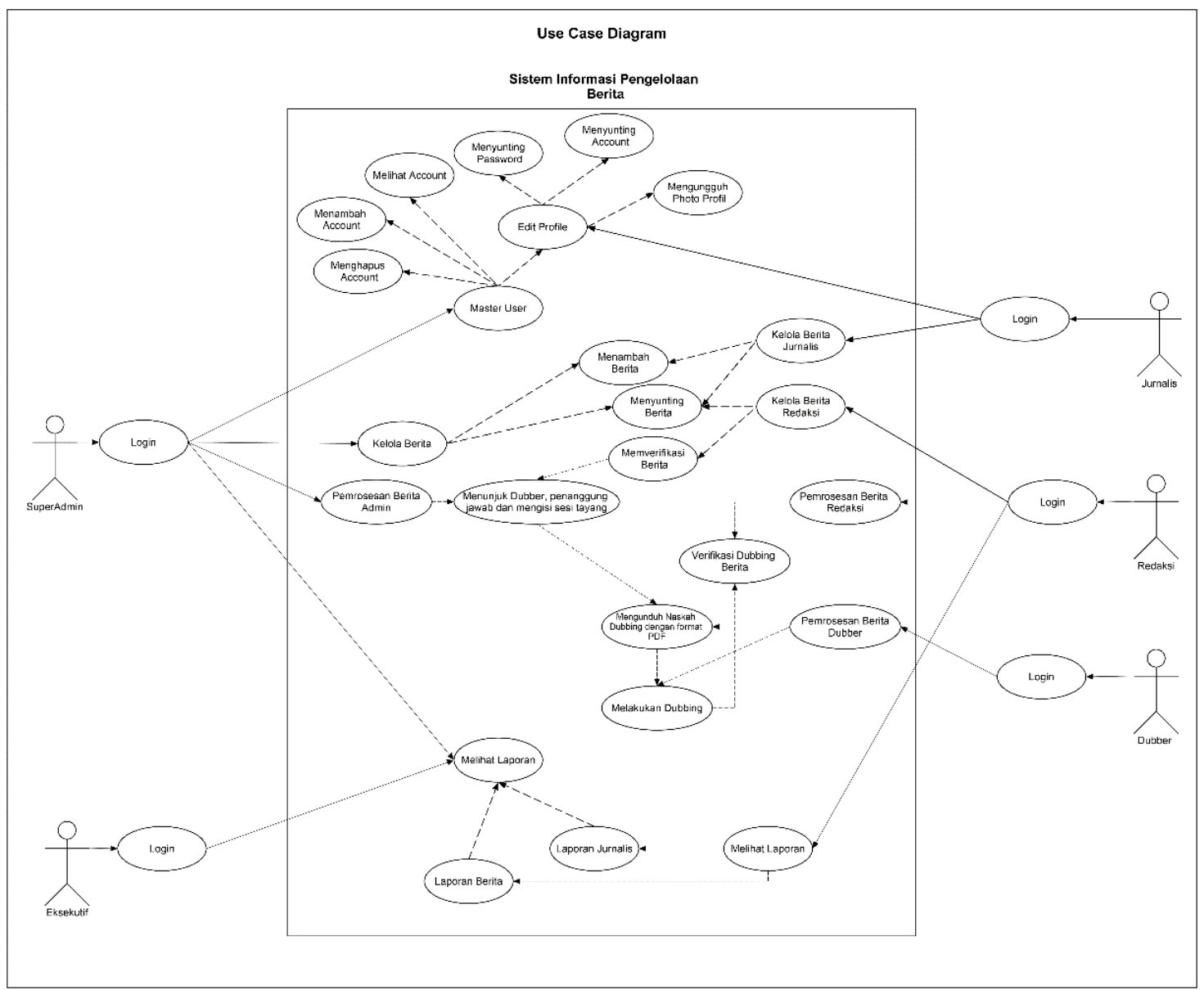

Gambar 3. Use case diagram

\section{b. Activity Diagram}

Gambar 4 merupakan penjelasan bagaimana aktor melakukan penambahan user atau pengguna sistem. 


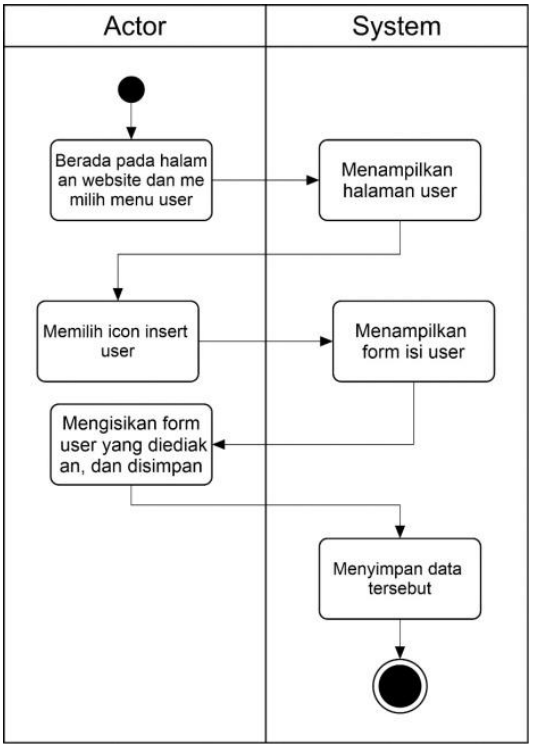

Gambar 4. Activity diagram tambah user

c. Sequence Diagram

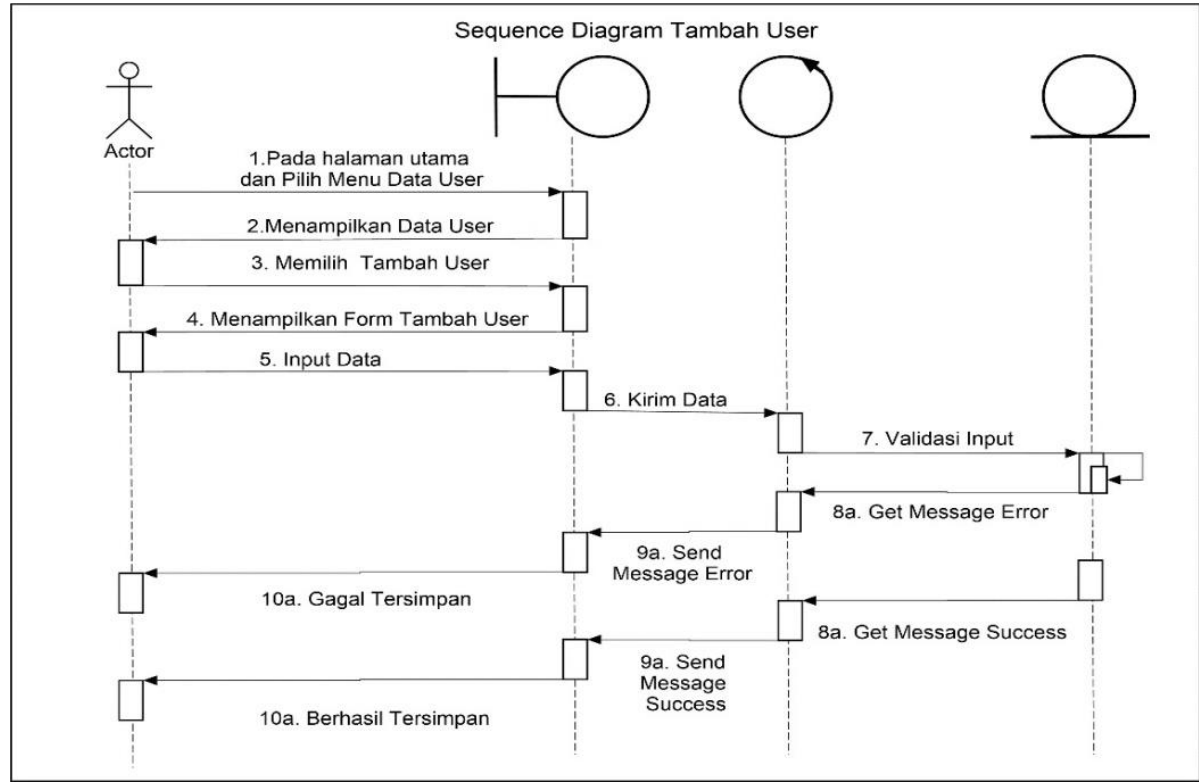

Gambar 5. Sequence diagram tambah user

Gambar 5 diatas menjelaskan tentang cara superadmin dalam menambahkan data pengguna sistem

\section{d. Class Diagram}

Class diagram menggambarakan struktur dan deskripsi class, package, dan object yang saling terkait. Class diagram pengeloalaan aset terdiri dari beberapa tabel yaitu tabel peminjaman, pengembalian, user, mutasi, accesories, hardware, software dan PC :

1) Tabel role digunakan untuk menyimpan data/informasi role user

2) Tabel kategori berita digunakan untuk menyimpan data/informasi kategori berita

3) Tabel user digunakan untuk menyimpan data/informasi user untuk mengakses sistem 
4) Tabel berita digunakan untuk menyimpan data/informasi berita

5) Tabel proses berita digunakan untuk menyimpan data/informasi proses berita

6) Tabel sesi digunakan untuk menyimpan data/informasi sesi

7) Tabel label verifikasi digunakan untuk menyimpan data/informasi label verifikasi

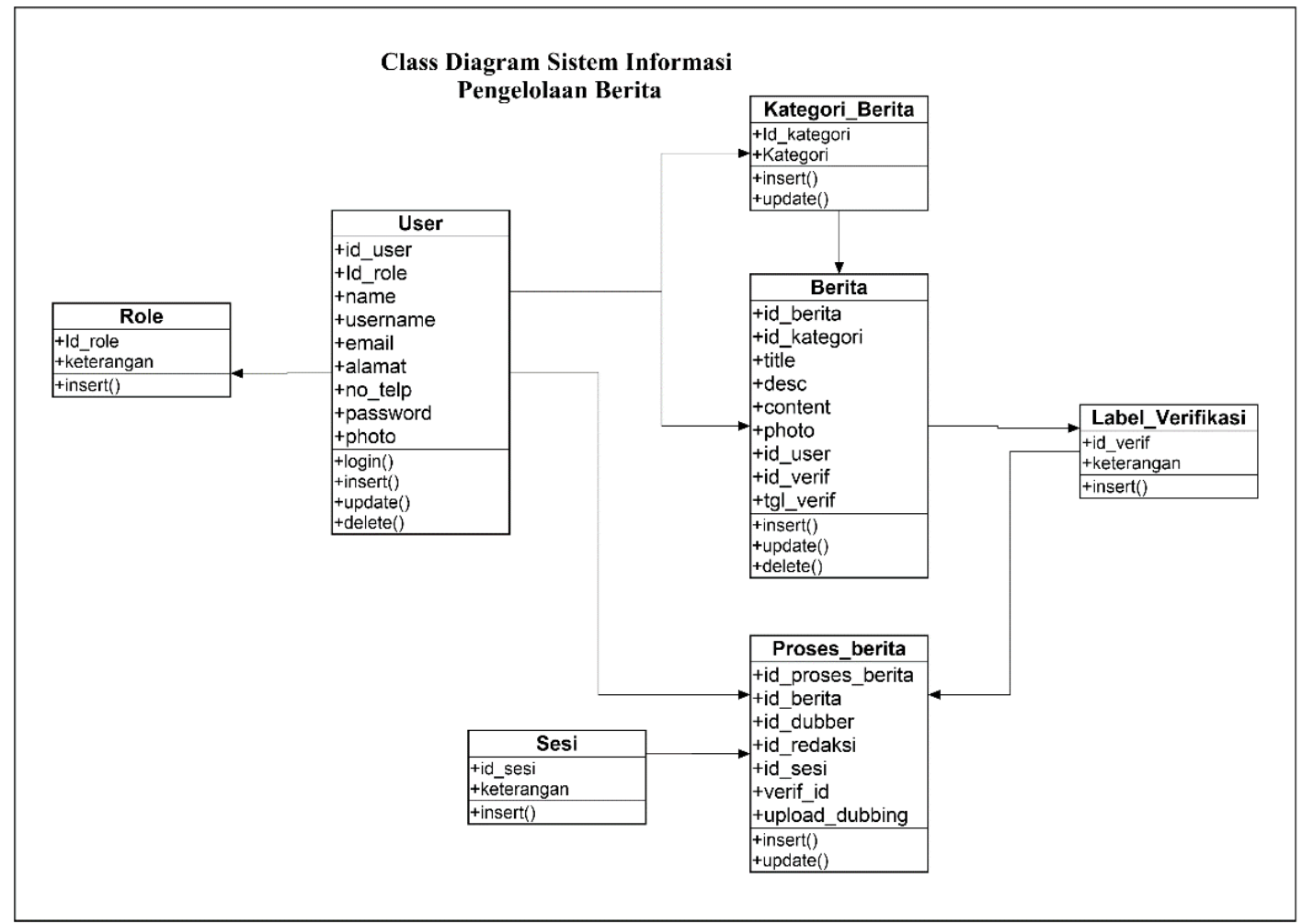

Gambar 6. Class diagram

\section{e. Mock Up Sistem}

Gambar 7 dibawah menjelaskan tentang tampilan halaman dashboard terkait sistem pengelolaan berita

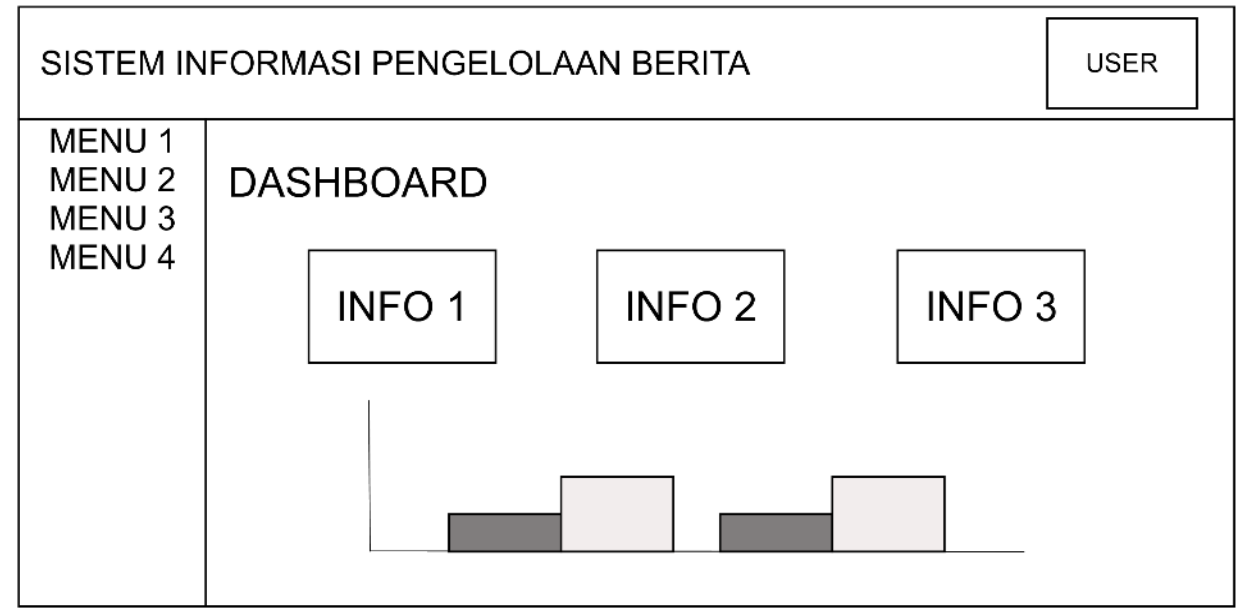

Gambar 7 Mock up halaman dashboard 


\section{Construction}

Pada tahapan ini akan dipaparkan proses peralihan dari tahap desain menjadi tahap produksi pembangunan sistem, proses pembangunan perangkat lunak terdiri dari serangkaian desain dan membangun.

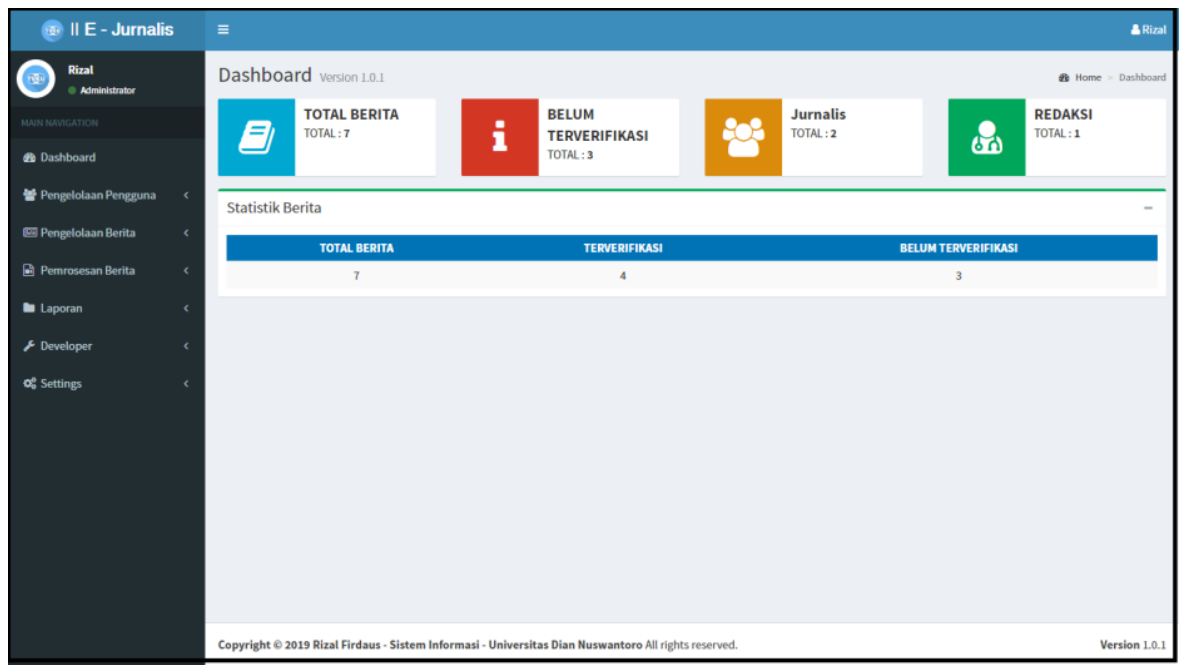

Gambar 8. Tampilan halaman dashboard

Halaman dashboard pada gambar 8 akan memberikan informasi mengenai beberapa detail dari berita yang belum di proses dan berita yang sudah di proses.

D. Implementasi

Setelah tahap consruction selesai maka dilanjutkan tahap pengujian system yang tampak pada tabel 1, untuk menguji apakah sistem telah sesuai dengan ekspektasi. Tahap pengujian menggunakan pendekatan metode Blackbox Testing Cause-Effect Relationship Testing.

Tabel 1. Blackbox testing

\begin{tabular}{|c|c|c|c|c|}
\hline \multicolumn{5}{|c|}{ Login } \\
\hline No & User Interface & Input & Output & Hasil Uji \\
\hline 1. & $\begin{array}{l}\text { Login dengan mengosongkan } \\
\text { username dan password pada } \\
\text { form login. }\end{array}$ & $\begin{array}{l}\text { Username = - } \\
\text { Password = - }\end{array}$ & $\begin{array}{l}\text { Hasil kotak } \\
\text { dialog “ Harap } \\
\text { Isi kolom ini “ }\end{array}$ & $\begin{array}{l}\text { Komponen } \\
\text { berjalan dengan } \\
\text { baik }\end{array}$ \\
\hline 2. & $\begin{array}{l}\text { Login dengan mengisikan } \\
\text { username dan mengosongkan } \\
\text { password pada form login. }\end{array}$ & $\begin{array}{l}\text { Username = (benar) } \\
\text { Password }=-\end{array}$ & $\begin{array}{l}\text { Hasil kotak } \\
\text { dialog “ Harap } \\
\text { Isi kolom ini “" }\end{array}$ & $\begin{array}{l}\text { Komponen } \\
\text { berjalan dengan } \\
\text { baik }\end{array}$ \\
\hline 3. & $\begin{array}{l}\text { Login dengan mengosongkan } \\
\text { username dan mengisikan } \\
\text { password pada form login. }\end{array}$ & $\begin{array}{l}\text { Username }=- \\
\text { Password }=(\text { benar })\end{array}$ & $\begin{array}{l}\text { Hasil kotak } \\
\text { dialog “ Harap } \\
\text { Isi kolom ini “" }\end{array}$ & $\begin{array}{l}\text { Komponen } \\
\text { berjalan dengan } \\
\text { baik }\end{array}$ \\
\hline 4. & $\begin{array}{l}\text { Login dengan mengisikan } \\
\text { username dan pada form } \\
\text { login. }\end{array}$ & $\begin{array}{l}\text { Username }=(\text { benar }) \\
=(\text { benar })\end{array}$ & $\begin{array}{l}\text { Masuk kedalam } \\
\text { halaman } \\
\text { dashboard }\end{array}$ & $\begin{array}{l}\text { Komponen } \\
\text { berjalan dengan } \\
\text { baik }\end{array}$ \\
\hline \multicolumn{5}{|c|}{ Menu Pengelolaan User/ Pengguna } \\
\hline No & User Interface & Input & Output & Hasil Uji \\
\hline 1. & Tambahkan User & Klik buat baru & $\begin{array}{l}\text { Muncul form } \\
\text { tambah } u \text { ser }\end{array}$ & $\begin{array}{l}\text { Komponen } \\
\text { berjalan dengan } \\
\text { baik }\end{array}$ \\
\hline 2. & Edit User & $\begin{array}{l}\text { Klik icon edit aset } \\
\text { pada kolom action }\end{array}$ & $\begin{array}{l}\text { Muncul } \\
\text { notifikasi edit? } \\
\text { Tekan iya, akan }\end{array}$ & $\begin{array}{l}\text { Komponen } \\
\text { berjalan dengan } \\
\text { baik }\end{array}$ \\
\hline
\end{tabular}




\begin{tabular}{|c|c|c|c|c|}
\hline 3. & Hapus User & $\begin{array}{l}\text { Klik icon delete pada } \\
\text { kolom action }\end{array}$ & $\begin{array}{l}\text { muncul form } \\
\text { edit } \\
\text { Muncul } \\
\text { notifikasi hapus? } \\
\text { Tekan iya maka } \\
\text { data akan } \\
\text { terhapus }\end{array}$ & $\begin{array}{l}\text { Komponen } \\
\text { berjalan dengan } \\
\text { baik }\end{array}$ \\
\hline \multicolumn{5}{|c|}{ Menu Pengelolaan Berita } \\
\hline \multicolumn{5}{|c|}{ Master Kategori Berita } \\
\hline No & User Interface & Input & Output & Hasil Uji \\
\hline 1. & Tambahkan Kategori Berita & Klik buat baru & $\begin{array}{l}\text { Muncul form } \\
\text { tambah user }\end{array}$ & $\begin{array}{l}\text { Komponen } \\
\text { berjalan dengan } \\
\text { baik }\end{array}$ \\
\hline 2. & Sunting Kategori Berita & $\begin{array}{l}\text { Klik icon edit aset } \\
\text { pada kolom action }\end{array}$ & $\begin{array}{l}\text { Muncul } \\
\text { notifikasi edit? } \\
\text { Tekan iya, akan } \\
\text { muncul form } \\
\text { edit }\end{array}$ & $\begin{array}{l}\text { Komponen } \\
\text { berjalan dengan } \\
\text { baik }\end{array}$ \\
\hline 3. & Hapus Kategori Berita & $\begin{array}{l}\text { Klik icon delete pada } \\
\text { kolom action }\end{array}$ & $\begin{array}{l}\text { Muncul } \\
\text { notifikasi hapus? } \\
\text { Tekan iya maka } \\
\text { data akan } \\
\text { terhapus }\end{array}$ & $\begin{array}{l}\text { Komponen } \\
\text { berjalan dengan } \\
\text { baik }\end{array}$ \\
\hline \multicolumn{5}{|c|}{ Kelola Berita } \\
\hline No & User Interface & Input & Output & Hasil Uji \\
\hline 1. & Tambahkan Berita & Klik buat baru & $\begin{array}{l}\text { Muncul form } \\
\text { tambah user }\end{array}$ & $\begin{array}{l}\text { Komponen } \\
\text { berjalan dengan } \\
\text { baik }\end{array}$ \\
\hline 2. & Sunting Berita & $\begin{array}{l}\text { Klik icon edit aset } \\
\text { pada kolom action }\end{array}$ & $\begin{array}{l}\text { Muncul } \\
\text { notifikasi edit? } \\
\text { Tekan iya, akan } \\
\text { muncul form } \\
\text { edit }\end{array}$ & $\begin{array}{l}\text { Komponen } \\
\text { berjalan dengan } \\
\text { baik }\end{array}$ \\
\hline 3. & Hapus Berita & $\begin{array}{l}\text { Klik icon delete pada } \\
\text { kolom action }\end{array}$ & $\begin{array}{l}\text { Muncul } \\
\text { notifikasi hapus? } \\
\text { Tekan iya maka } \\
\text { data akan } \\
\text { terhapus }\end{array}$ & $\begin{array}{l}\text { Komponen } \\
\text { berjalan dengan } \\
\text { baik }\end{array}$ \\
\hline \multicolumn{5}{|c|}{ Menu Pemrosesan Berita } \\
\hline No & User Interface & Input & Output & Hasil Uji \\
\hline 1. & Mengisi Dubber Berita & $\begin{array}{l}\text { Pilih aksi lalu pilih } \\
\text { proses berita }\end{array}$ & $\begin{array}{l}\text { Muncul form } \\
\text { proses berita }\end{array}$ & $\begin{array}{l}\text { Komponen } \\
\text { berjalan dengan } \\
\text { baik }\end{array}$ \\
\hline 2. & Mengunduh naskah berita & $\begin{array}{l}\text { Pilih aksi cetak } \\
\text { naksah berita }\end{array}$ & $\begin{array}{l}\text { Muncul pada } \\
\text { halaman lain } \\
\text { naskah berita }\end{array}$ & $\begin{array}{l}\text { Komponen } \\
\text { berjalan dengan } \\
\text { baik }\end{array}$ \\
\hline 3. & Meunggah dubbing berita & Pilih aksi upload & $\begin{array}{l}\text { Muncul } \\
\text { pencarian data }\end{array}$ & $\begin{array}{l}\text { Komponen } \\
\text { berjalan dengan } \\
\text { baik }\end{array}$ \\
\hline 4. & Verifikasi dubbing berita & $\begin{array}{l}\text { Pilih aksi lalu pilih } \\
\text { proses berita }\end{array}$ & $\begin{array}{l}\text { Muncul form } \\
\text { proses berita }\end{array}$ & $\begin{array}{l}\text { Komponen } \\
\text { berjalan dengan } \\
\text { baik }\end{array}$ \\
\hline \multicolumn{5}{|c|}{ Menu Rekap Data } \\
\hline No & User Interface & Input & Output & Hasil Uji \\
\hline 1. & Cetak laporan & Klik icon print & $\begin{array}{l}\text { Laporan } \\
\text { keseluruhan } \\
\text { tanpa filter }\end{array}$ & $\begin{array}{l}\text { Komponen } \\
\text { berjalan dengan } \\
\text { baik }\end{array}$ \\
\hline
\end{tabular}




\begin{tabular}{|c|c|c|c|c|}
\hline 2. & $\begin{array}{l}\text { Cetak laporan dengan filter } \\
\text { jurnalis }\end{array}$ & Klik icon print & $\begin{array}{l}\text { Laporan sesusai } \\
\text { dengen filter } \\
\text { jurnalis }\end{array}$ & $\begin{array}{l}\text { Komponen } \\
\text { berjalan dengan } \\
\text { baik }\end{array}$ \\
\hline 3. & $\begin{array}{l}\text { Cetak laporan dengan filter } \\
\text { status berita }\end{array}$ & Klik icon print & $\begin{array}{l}\text { Laporan sesuai } \\
\text { dengan filter } \\
\text { status berita }\end{array}$ & $\begin{array}{l}\text { Komponen } \\
\text { berjalan dengan } \\
\text { baik }\end{array}$ \\
\hline
\end{tabular}

\section{KESIMPULAN}

Kesimpulan pada penelitian yang dapat diambil adalah terciptanya suatu system informasi pengelolaan berita yang dapat mempermudah dalam melakukan manajemen berita pada PT TVKU Semarang khususnya bagian program dan produksi. Dengan adanya system ini akan memudahkan jurnalis dan redaksi dalam melakukan proses pengelolaan berita yang masuk kedalam system, melakukan pemrosesan berita, dan terintegrasinya data atau informasi, sehingga berita yang masuk ke dalam sistem mudah dilakukan pemantauan melalui tampilan dashboard pada system.

\section{SARAN}

Berdasarkan hasil perancangan dan implementasi sistem informasi pengelolaan berita pada PT TV Kampus UDINUS perlu dilakukan pengembangan selanjutnya dengsn mengembangkan perangkat lunak secara maksimal, dimana pada system pengelolaan berita dapat mendeteksi suatu tindakan plagiasi atau plagiat terhadap suatu karya atau keaslian data berita dari pada setiap jurnalis. Untuk penelitian selanjutnya diharapkan system dapat dikembangkan menjadi suatu aplikasi yang dapat berbasis iOS / Android, agar dapat memudahkan jurnalis dalam melakukan pendataan berita.

\section{DAFTAR PUSTAKA}

[1] I. P. Setiawan and N. Miyono, "Perancangan Sistem Informasi Manajemen Berita Berbasis Web (Studi Kasus Kantor Redaksi Koran Wawasan)”, vol. 2013, pp. 9-16, 2013.

[2] J. Martin, "Rapid Application Development", Macmillan., 1991.

[2] N. Hidayati and M. Informatika, "Penggunaan Rapid Application Development Dalam Rancang Bangun Program Simpan Pinjam Pada Koperasi”, vol. 2, no. 2, pp. 87-97, 2018.

[3] D. A. Arista et al., "Pengembangan sistem informasi manajemen aset dengan metode rappid applicaton development," no. 12, 2010.

[4] S. Dharwiyanti and R. S. Wahono, "Pengantar Unified Modeling Language (UML)," IlmuKomputer.com, pp. 1-13, 2003.

[5] A. B. Warsito, I. Handayani, and Y. Dewi, "Sistem Berita Online Berbasis Web Pada," pp. 6-7, 2016. 